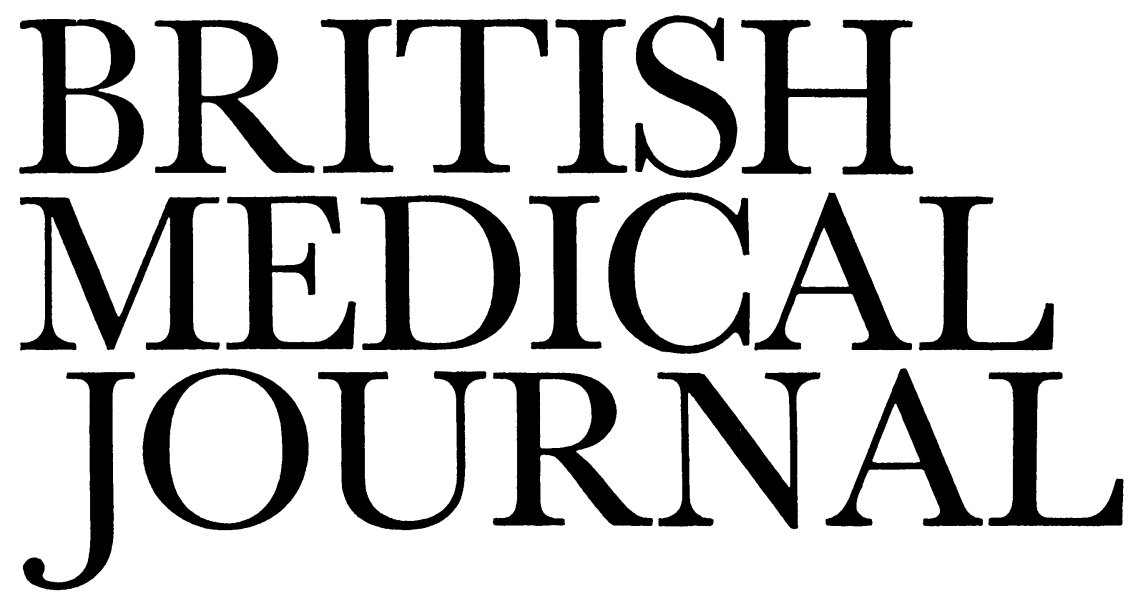

LONDON, SATURDAY 7 MAY 1983

\title{
Malaria and pregnancy
}

The recent spate of reports ${ }^{1}$ confirming the extension to parts of east Africa of chloroquine resistant strains of Plasmodium falciparum, which have been present for some time in other parts of the tropical world, ${ }^{2}{ }^{3}$ has caused much concern. Travel for business or pleasure has now become commonplace: in 1981 some 19 million Britons spent their holidays abroad, and many of them went to various exotic areas. ${ }^{4}$ No wonder, then, that the news of changing trends in prevention of malaria by hitherto reliable drugs has caused some disquiet. In particular, many women want answers to three important questions. Does pregnancy aggravate malaria and vice versa? Can the available drugs always protect from malaria infection? Does the prevention of infection by antimalarial drugs have an adverse effect on the pregnancy or on the unborn child? Much has been written on these three topics and some aspects remain uncertain, but a consensus of expert opinion may be given.

Malaria in general, and especially an infection with $P$ falciparum, is more hazardous during pregnancy. Pregnancy appears to interfere with the immune processes in malaria, ${ }^{5-7}$ a disease which itself alters immune reactivity. ${ }^{8}$ In highly endemic malarious areas, where semi-immune adults usually have substantial acquired resistance to local strains of plasmodia, the prevalence of clinical malaria is higher and its severity greater in pregnant women, especially during the second trimester, with the greatest risk in primiparas. ${ }^{5} 7910$

The mechanism of this phenomenon is complex, with evidence of both suppression of antibody formation and depression of cell mediated immunity. ${ }^{8}$ Malaria may cause abortion and premature labour; in tropical areas many pregnant women suffer from severe anaemia due to the infection itself and to the effects of deficiency of iron and folic acid. ${ }^{11} 12$ The results of recent studies indicate that the anaemia of malaria is due to some extent to the immune destruction of sensitised red cells and a depression of erythropoiesis. ${ }^{13}$

Acute malaria in a pregnant woman requires speedy and complete treatment by the most effective drugs available, with full supporting medication. ${ }^{10121415}$ Any fear that quinine at high therapeutic dosage may cause abortion is greatly exaggerated-and, moreover, severe malaria presents a far greater danger to the mother and the fetus. Congenital transmission of malaria may occur, though it is relatively rare; paradoxically, it is more frequent in babies born of non-immune mothers with malaria imported from tropical countries, though massive infections of the placenta with $P$ falciparum are common in immune mothers in highly endemic areas. ${ }^{5}$ 9-12 1416

Chemoprophylaxis of malaria throughout pregnancy, but particularly during its last third, is imperative for all nonimmune women visiting endemic malarious areas. Prophylaxis is also advisable for all women permanently resident in tropical countries where malaria occurs. ${ }^{317-20}$ The previously wide range of effective drugs available for chemoprophylaxis has now become restricted, because of the widespread resistance of $P$ falciparum to antifolates (proguanil, pyrimethamine, trimethoprim) and the slow but steady extension of this resistance to 4-aminoquinolines (chloroquine, amodiaquine) and also to other drugs. ${ }^{18}$ The use of a combination of pyrimethamine with sulfadoxine (Fansidar) or with dapsone (Maloprim) for preventing malaria in pregnant women is controversial, because of the alleged but unproved embryopathic action of pyrimethamine or possible effects of longlasting sulphonamides on the blood forming organs of the fetus. For this reason Fansidar is not recommended for malaria prophylaxis in pregnancy by the World Health Organisation $^{3}$ or by its makers. Views are divided on the combination of pyrimethamine with dapsone (Maloprim). There is no evidence of any embryopathic effects when Maloprim is given at the recommended adult dose of one tablet a week. This dosage is adequate for fairly good protection from $P$ falciparum malaria, even though the pharmacodynamics of the two active components are not well matched. ${ }^{21718} \mathrm{At}$ higher dosage Maloprim may depress the bone marrow. In Britain expert opinion maintains that provided a woman takes folic or folinic acid (10 mg) daily she may take Maloprim during pregnancy; avoidance of the drug is not, we believe, justified by the evidence. Maloprim is not, however, recommended in France or the United States or by the World Health Organisation. ${ }^{3}$ Furthermore, neither of the pyrimethamine-sulfadoxine or pyrimethamine-dapsone combinations are adequate for preventing malaria in areas with a high degree of resistance of $P$ falciparum to pyrimethamine, or for full protection from infection with $P$ vivax.

The conclusion seems to be that chloroquine and amodiaquine are still the best and comparatively the least harmful drugs for protecting pregnant women against $P$ vivax, $P$ malariae, $P$ ovale, and chloroquine sensitive strains of $P$ falciparum. Even in areas with some plasmodial resistance 
to chloroquine fair protection will probably be obtained from a regular weekly dosage of $300 \mathrm{mg}$ of chloroquine base during the stay in the endemic area and for at least four weeks after return to a temperate climate. ${ }^{18}$ Should a breakthrough occur other antimalarials will have to be used for treatment, including mefloquine when it becomes more widely available. ${ }^{15}$

Primaquine, normally used for preventing relapses in $P$ vivax malaria, should be avoided or used with great caution in any pregnant woman with a risk of deficiency of glucose-6phosphate dehydrogenase. There is no evidence that chloroquine chemoprophylaxis causes any toxic effects on the eye or any congenital defects when given at the standard adult dosage of $300 \mathrm{mg}$ base a week for as long as four to five years. ${ }^{17}$ Adverse effects of chloroquine on the auditory system of the newborn were reported when the drug was given in very high dosage to pregnant women with rheumatoid arthritis and similar diseases. No such effects have been reported from malaria prophylaxis.

Like most of the other antimalarial drugs chloroquine crosses the placenta and appears in small amounts in maternal milk, ${ }^{10}$ but this does not provide a full safeguard for the newborn baby, and the time honoured methods of protection from mosquito bites (bed nets, space sprays, and so on) need to be used. ${ }^{3}$

Finally, a traditional and usually unwelcome piece of advice given to any woman in her second half of pregnancy is to forgo any exotic travels unless unavoidable.

\section{J BRUCE-ChWATt}

Emeritus Professor of Tropical Hygiene,

University of London

Wellcome Museum of Medical Science,

London NW1 2 BP

'Bruce-Chwatt LJ. Chemoprophylaxis of malaria in Africa: the spent "magic bullet." $\mathrm{Br} \mathrm{Med} \mathcal{F} 1982$;285 :674-6.

${ }^{2}$ Peters W. Antimalaria drug resistance: an increasing problem. $\mathrm{Br} \mathrm{Med}$ Bull $1982 ; 38: 187-92$.

${ }^{3}$ World Health Organisation. Malaria chemoprophylaxis. World Health Organisation Weekly Epidemiological Record 1982;57:381-4.

+ Walker E, Williams G. Problems facing the traveller. Br Med $\mathcal{F} 1983$; 286:541-3.

${ }^{5} \mathrm{McGregor} \mathrm{IA.} \mathrm{Immunology} \mathrm{of} \mathrm{malarial} \mathrm{infection} \mathrm{and} \mathrm{its} \mathrm{possible} \mathrm{con-}$ sequences. Br Med Bull 1972;28:22-7.

6 Cohen S. Immunity to malaria. Proc R Soc Lond (Biol) 1979;203:323-45.

7 Playfair JHL. Immunity to malaria. Br Med Bull 1982;38:153-9.

${ }^{8}$ Weidanz WP. Malaria and alterations in immune reactivity. Br Med Bull 1982;38:167-72.

${ }^{9}$ Bray RS, Anderson MJ. Falciparum malaria and pregnancy. Trans $R$ Soc Trop Med Hyg $1979 ; 73: 427-31$.

10 Adams ARD, Maegraith BG. Clinical tropical diseases. 7th ed. Oxford: Blackwell Scientific Publications, 1980.

11 Bruce-Chwatt LJ. Malaria. In: Jelliffe DB, Stanfield JP, eds. Diseases of children in subtropics and tropics. 3rd ed. London: Edward Arnold, 1978:827-56.

12 Woodruff AW, ed. Medicine in the tropics. Edinburgh: Churchill Livingstone, 1974

13 Weatherall DJ, Abdalla S. Anaemia of Plasmodium falciparum malaria. Br Med Bull 1982;38:147-52.

14 Gilles HM. The management and treatment of malaria. (A personal view.) Ann Soc Belg Med Trop 1980;60:129-36.

${ }^{15}$ Hall AP. The treatment of severe falciparum malaria. Trans $R$ Soc Trop Med Hyg 1977;71:367-79.

18 Manson Bahr PEC, Apted FI. Manson's tropical diseases. 18th ed. London: Baillière Tindall, 1982.

17 Bruce-Chwatt LJ (ed), Black RH, Canfield CJ, Clyde DF, Peters W, Wernsdorfer WH. Chemotherapy of malaria. 2nd ed. Geneva: World Health Organisation, 1981. (WHO Monograph Series No 27.)

${ }^{18}$ Ross Institute. Malaria prevention in travellers from the United Kingdom. Br Med F $1981 ; 283: 214-8$.

19 Rollo IM. Drugs used in the chemotherapy of malaria. In: Gilman AG, Goodman ALS, Gilman A, eds. The pharmacological basis of therapeutics. 6th ed. New York: Macmillan, 1980:1038-60.

${ }^{20}$ American Public Health Association US Administration for International Development. Manual for malaria control in primary health care in Africa. Washington DC: APHA, 1982.

\section{A cooler look at lead}

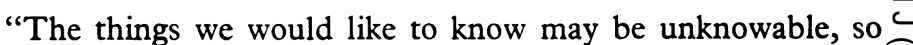
there is some virtue in just getting rid of the problem," said $\mathrm{Sir} \cong$ James Gowans, commenting on the issue of lead and intelli- $\bar{T}$ gence at the end of a conference on lead held in Cardiff last $\$$ week. Organised by the Medical Research Council Epidemio- $m$

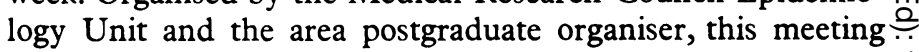
came in the wake of the Royal Commission on Environmental Pollution's report recommending the removal of lead from $\frac{?}{0}$ petrol. ${ }^{1}$ Now that the Government's decision on petrol has put $\frac{C}{0}$ an end to this long and bitter controversy, a cooler look can be $\overline{\bar{\omega}}$ taken both at the scientific questions and at the other practical $\stackrel{\odot}{\varnothing}$ actions that are needed.

The royal commission reached its conclusion on grounds of $\vec{\infty}$ prudence, without making any judgment about the evidence? on the effects of low concentrations of lead on children's $\vec{\omega}$ intelligence and behaviour. It was particularly worried that $\frac{\mathscr{\partial}}{\partial}$ such a persistent and widely distributed toxin as lead should 3 have so narrow a safety margin, but its conclusions were "not dependent on the precise accuracy of any particular investigation or calculation." This approach is welcomed by the BMF, ⿷匚 which has for some time urged the abolition of lead from petrol ? while remaining agnostic about some of the scientific evidence. ${ }^{2} \vec{f}$

Nevertheless, the effects of low concentrations of lead on children are still relevant to the urgency and the extent of the 9 various practical actions recommended by the royal com- $v$ mission. In the last session of the Cardiff conference Marjorie Smith reviewed the evidence, including the Institute of Child $\vec{\bullet}$ Health and Southampton University study with which she was concerned and two others reported recently at the British Psychological Society's annual conference in York. The first of these three studies, on tooth lead in 6-7 year old London children, is the most extensive and detailed yet carried out. On the IQ scales and the reading test there were significant $\stackrel{\circ}{\varnothing}$ differences between the "high," "medium," and "low lead" groups; but after social variables were allowed for the differences became non-significant. The other two recent studies similarly showed differences in performance favouring children with the lower lead burdens but these too turned out to be non-significant.

What are we to make of these findings, taken in conjunction with the more positive earlier reports (reviewed in a recently published symposium $\left.{ }^{3}\right)$ ? All the trends are in the same of direction, and Marjorie Smith did not believe that they could $₹$ be attributed to chance. Nevertheless, since controlling for all 은 social variables was impossible the differences could well have $N$ resulted from social factors rather than differences in body $D$ burdens of lead-and if there was in truth a "signal" due to lead, she concluded, it might be undetectable amidst the $N$ "noise" of other factors. Rutter has presented arguments for accepting that the trends do represent a genuine though smallo effect of lead; and he makes two further important points- $O$ that an average reduction in IQ of only a few points in any group of children implies more damaging impairment in some of them, and that a given dose of lead may possibly do more $\frac{7}{0}$ harm to the socially disadvantaged children. ${ }^{3}$

Wherever the truth lies, there is a strong enough possibility $\frac{O}{\mathbb{D}}$ of risk to justify energetic measures against lead exposure of all kinds. Lead in water still needs action. ${ }^{1}$ Replacement of lead pipes gives a dramatic fall in both water and blood lead con-응 centrations ${ }^{45}$ but it costs some $£ 600$ a house and the work proceeds slowly. But for once the cheap solution begins to look like the superior one, and P C Elwood discussed the arguments 